\title{
A rare case of acute non-puerperal uterine inversion due to large leiomyoma in COVID pandemic: challenges in clinical diagnosis and management
}

\author{
Snehal G. Murde*, Rohini R. Raut, Beena Kumari, Dinesh C. Hojai
}

Department of Obstetrics and Gynaecology, Dr Babasaheb Ambedkar Memorial Hospital, Byculla, Mumbai, Maharashtra, India

Received: 05 September 2020

Accepted: 07 October 2020

\section{*Correspondence:}

Dr. Snehal G. Murde,

E-mail: snehalmurde@gmail.com

Copyright: (c) the author(s), publisher and licensee Medip Academy. This is an open-access article distributed under the terms of the Creative Commons Attribution Non-Commercial License, which permits unrestricted non-commercial use, distribution, and reproduction in any medium, provided the original work is properly cited.

\begin{abstract}
Non puerperal uterine inversion is a very rare clinical scenario with very few gynaecologist actually managing it in their lifetime. Acute variety of non-puerperal inversion is even rarer and thus possess diagnostic and management challenges. Case study of a rare case of a 45 years old female who was admitted for an elective surgery and had sudden acute inversion of uterus which was clinically diagnosed. Patient was managed by debulking of tumour which turned out to be large leiomyoma, followed by total abdominal hysterectomy. Rarity of the disease, atypical symptoms and less clinical exposure to such cases pose diagnostic as well as surgical challenges as in our case.
\end{abstract}

Keywords: Acute, Uterine inversion, Non-puerperal

\section{INTRODUCTION}

Uterine inversion is a rare but life-threatening complication in which uterus turns inside out and prolapses out of cervix. Incidence of puerperal inversion is approximately 1 in 3500 deliveries however incidence of non-puerperal uterine inversion is largely unknown. ${ }^{1}$ Nonpuerperal uterine inversion (NPUI) is a rare clinical problem with diagnostic and surgical challenges; with only 170 case reports since $1940 .^{2}$ Inversion of the uterus was classified by Jones in 1951 into two types: puerperal or obstetric and nonpuerperal or gynaecological. ${ }^{3}$ The nonpuerperal type is caused mostly by benign or malignant tumours associated with the uterine corpus. Nonpuerperal inversions present mostly as chronic cases, although only $8.6 \%$ of nonpuerperal inversion as a sudden onset. ${ }^{4}$ Most of the published literature on non-puerperal uterine inversions is in form of case reports. Leiomyoma is the commonest cause for NPUI other causes being carcinomas and sarcomas and other rare causes. Diagnosing a case of non-puerperal uterine inversion is difficult and requires high degree of suspicion. Surgical challenges faced are due to the rarity of this condition which leads to lack of surgical expertise in handling such rare cases, difficulty in reducing a non-puerperal inversion and finally decision on choosing the route of surgery ultimately leading to prolonged operating time and morbidity in patient.

\section{CASE REPORT}

A 45 years old female para 3 was admitted at our hospital with complaints of heavy menstrual bleeding since 10 days not relieved on oral medications. She also had complaints of foul-smelling white discharge per-vaginum and pain in abdomen since 10 days. Patient had 3 full term vaginal delivery which were uneventful. Last delivery was 16years back. Patient did not know her last menstrual period but there was continuous bleeding since 10 days. Her previous cycles were regular with heavy flow for 6-7 days once in 
30 days. There was no significant past history and no significant family history.

On admission she was conscious, oriented, averagely built and nourished. She was pale, had tachycardia and was normotensive. Other systemic examination was normal. On per abdomen examination there was tenderness in lower abdomen. No abnormal mass felt. No scars, or sinuses. On per speculum examination, purulent blood tinged discharge present. Cervical mass seen not protruding from os. On per vaginal examination uterus was about 14 weeks size. About $8 \times 10 \mathrm{~cm}$ cervical mass felt. Bilateral fornices were free. On per rectal examination bilateral parametrium was free and rectal mucosa was free.

On investigation her haemoglobin was $7.2 \mathrm{mg} / \mathrm{dl}$ and other blood parameters were normal. Ultrasonography was suggestive of an arcuate/septate shaped uterus. $8 \times 7.5 \mathrm{~cm}$ fibroid seen in lower uterine segment protruding in cervix seen. Bilateral ovaries and adnexa normal. Patient was planned for an elective myomectomy sos hysterectomy after routine investigations along with Real-timePolymerase chain reaction (RT-PCR) for Severe acute respiratory syndrome coronavirus-2 (SARS COV-2) and preoperative preparation. Two units packed cells were arranged pre-operatively and patient was started on oral antifibrinolytics and antibiotics. We were awaiting reports of investigations however patient started complaining of very severe lower abdominal pain after straining for stools. Pain was acute onset, dragging, localised to lower abdomen and perineum along with sensation of something coming out per vaginum on standing and acute urinary retention. Foleys catheterisation done and $1000 \mathrm{ml}$ urine drained. On examination large mass seen outside vagina, cervical os not seen. A clinical diagnosis acute nonpuerperal uterine inversion secondary to uterine fibroid was made and patient was shifted to emergency Operation theatre (OT).

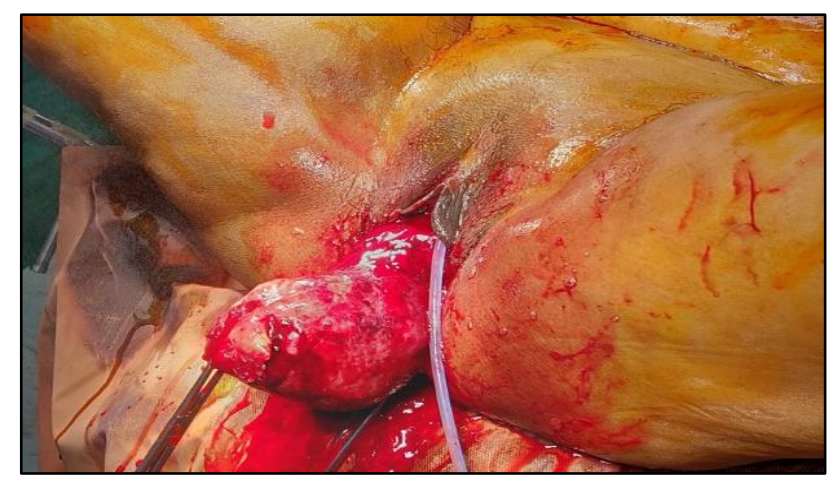

Figure 1: Large leiomyoma causing acute inversion.

Manual reduction of uterine inversion tried vaginally however was not successful and subsequent decision of laparotomy taken. Abdomen opened in layers and the intraoperative findings noted confirming the diagnosis of complete uterine inversion.
Huntington procedure to reposit uterus back in abdominal cavity tried by clamping bilateral round ligaments and fundus and by applying gentle traction. However due to the leiomyoma size uterus couldn't be repositioned. Surgery proceeded further by clamping and cutting bilateral round ligaments followed by bilateral cornual and fundal structures. After clamping and cutting bilateral uterine arteries, uterus was cut opened by a midline vertical incision and intramural fibroid of size $8 \times 8 \mathrm{~cm}$ removed, and total hysterectomy completed thereafter. The specimen sent for histopathological examination, confirmed the finding of leiomyoma.

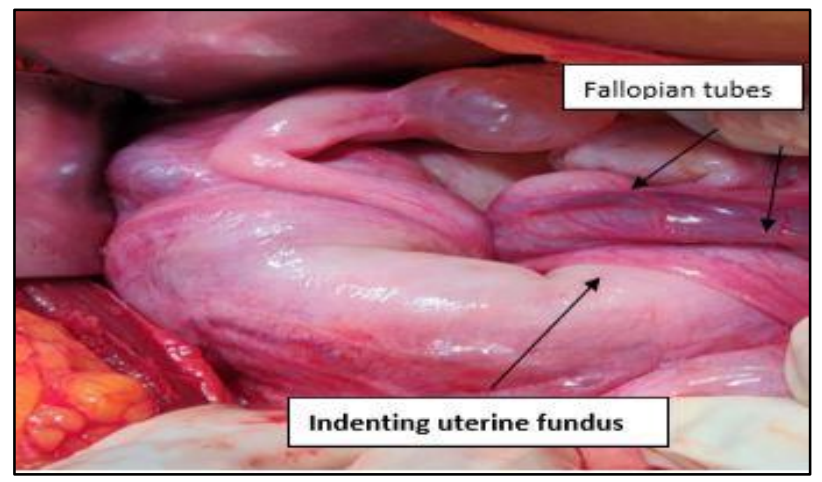

Figure 2: Intraoperative - flower vase appearance of inversion.

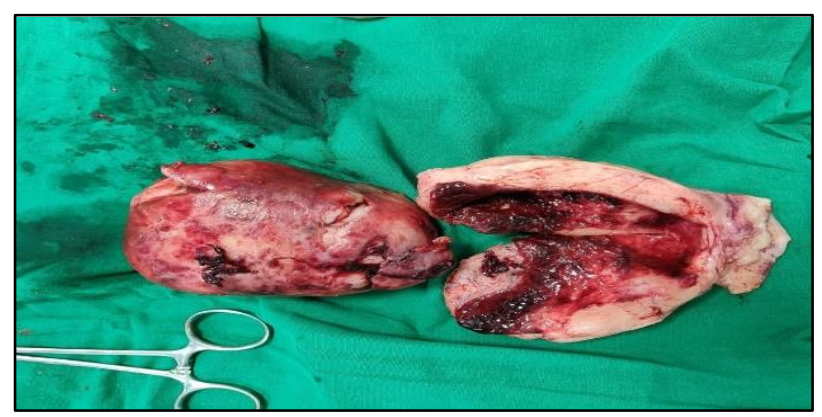

Figure 3: Gross specimen of leiomyoma and uterus.

Patient tolerated surgery well and postoperative period was uneventful. Patient was discharged on post-operative day 4 .

\section{DISCUSSION}

Uterine inversion that too a non- puerperal type is a very rare clinical problem faced by very few gynecologist in their entire career. Very few cases of acute form of nonpuerperal uterine inversion have been studied in literature with its incidence being just $8.6 \% .^{4}$ Uterine inversion has been classified as per degree of descent as in table $1 .^{5}$

The symptoms with which the patients present are nonspecific ranging from lower abdominal pain, white discharge per vaginum, heavy menstrual bleeding fulness of vagina and mass coming out per vaginum.6 Few patients also present with acute urinary retention requiring 
immediate catheterisation. As in our case as it was not a chronic inversion patient presented with heavy menstrual bleeding, pain in abdomen and discharge per vaginum. But when the uterine inversion actually occurred patient had different symptoms as mentioned above including acute retention of urine. Very few patients present with hypovolemic shock in case of acute inversion due to fibroid. ${ }^{7}$ Patients are usually anaemic, and their mean haemoglobin was found to be requiring preoperative and intraoperative packed cell transfusion. ${ }^{7,8}$

\section{Table 1: Classification of uterine inversion as per degree of descent.}

\begin{tabular}{|ll|}
\hline Stages & Degree of descent of uterus \\
\hline Stage & $\begin{array}{l}\text { Inversion of uterus is incomplete. The } \\
\mathbf{1}\end{array}$ \\
\hline $\begin{array}{l}\text { Stage } \\
\mathbf{2}\end{array}$ & $\begin{array}{l}\text { Complete inversion of uterine fundus } \\
\text { through fibromuscular ring of cervix. }\end{array}$ \\
\hline $\begin{array}{l}\text { Stage } \\
\mathbf{3}\end{array}$ & $\begin{array}{l}\text { Total inversion, whereby the fundus } \\
\text { protrudes through vulva. }\end{array}$ \\
\hline $\begin{array}{l}\text { Stage } \\
\mathbf{4}\end{array}$ & $\begin{array}{l}\text { The vagina is also involved with complete } \\
\text { inversion through the vulva along with the } \\
\text { inverted uterus. }\end{array}$ \\
\hline
\end{tabular}

The real challenge in non-puerperal inversion faced is that due to rarity of the condition. The diagnosis is difficult and requires high degree of suspicion especially when inversion is partial. ${ }^{9}$ The dilemma faced such as choosing the approach to surgery, changing the route of surgery from vaginal to abdominal approach is very common scenario due to inability of resection of the tumour vaginally due to necrosis and its chronicity. Also more preoperative time due to lack of surgical expertise as it is a non-routine surgery.

There are two approaches to surgery after reduction of the inversion- abdominal approach includes: Huntington's and Haultain.

In Huntington technique the cup or dimple of the inversion is identified, Allis forceps are introduced into the cup and placed on the round ligaments, and gentle upward traction is exerted on the clamps containing the ligaments. While further upward pressure is exerted on the advancing uterus, traction is continually applied on the ligaments until correction of the inversion is accomplished.

In Haultain's technique, the technique utilized in this case, a longitudinal incision is made in the posterior uterine wall and through the cervical constriction ring. This releases the constrictive pressure and facilitates anatomical restoration of the uterus with continued upward pressure until it reverts to normal positioning.

Vaginal approaches includes: Spinelli’s and Kustner

The Spinell's operation for chronic inversion of the uterus: The bladder is dissected from the inverted uterus. A midline split is made in the cervix and it is carefully separated from the bladder. The anterior wall of the everted uterus is split. Then the uterus is turned outside in. The myometrium is reapproximated by two layers of running suture, and the serosal surface by a single layer. The vaginal skin is reapproximated with interrupted sutures, as is the full thickness of the cervix.

The Kustner's operation for chronic inversion of the uterus: After opening the posterior cul-de-sac the cervix and posterior wall of the uterus are incised. On completion of this step, thumb pressure along the sides of the uterus produce reversion, Interrupted sutures are used to close the incisions and the uterus replaced in the pelvic cavity. This is followed by closure of the colpotomy.

\section{CONCLUSION}

Acute non-puerperal uterine inversion is a very rare condition and the most common cause of it being uterine leiomyoma. It is difficult to manage even for the experienced gynecologists and many surgeons face dilemma in choosing the approach to surgery. Most of the surgeons choose Abdominal Hysterectomy as the surgery of choice. The importance of histopathological examination cannot be over emphasized to rule out malignancy. It has a good prognosis if managed timely.

\section{ACKNOWLEDGMENTS}

We acknowledge the help our entire team of obstetricians, anaesthetist, Operation theatre staff for their help and cooperation. The woman and her whose story is told in this case report cooperated in our work signed permission for its publication.

\section{Funding: No funding sources Conflict of interest: None declared Ethical approval: Not required}

\section{REFERENCES}

1. Baskett, Thomas F. Acute uterine inversion: a review of 40 cases. J Obstet Gynaecol. 2002;24(12):953-6.

2. Rosa Silva B, Meller F, Uggioni ML, Grande AJ, Silva CN, Colonetti $\mathrm{T}$ et al. Non-Puerperal Uterine Inversion: A Systematic Review. Gynecol Obstet Invest. 2018;83:428-36.

3. Jones HW. Non-puerperal inversion of the uterus. Amer J Surg. 1951;81(5):492-5.

4. Das P. Inversion of the uterus. J Obstet Gynaecol Br Emp. 1940;47:527-48.

5. Wendel PJ, Cox SM. Emergent obstetric management of uterine inversion. Obstet Gynecol Clin North Am. 1995;22(2):261-74.

6. Skinner GN, Louden KA. Non-puerperal uterine inversion associated with an atypical leiomyoma. J Obstet Gynaecol. 2001;41(1):100-1. 
7. Song YJ, Yang J, Yun HS, Lee SK, Kim HG, Lee DH et al. Non-puerperal uterine inversion presented with hypovolemic shock. J Menop Med. 2016;22(3):184-7.

8. Fofie CO, Baffoe P. Non-puerperal uterine inversion: a case report. Ghana medical journal. 2010;44(2):7981.

9. Takano K, Ichikawa Y, Tsunoda H, Nishida M. Uterine inversion caused by uterine sarcoma: a case report. Jpn J Clin Oncol. 2001;31(1):39-42.

10. Shamsudin F, Morton K. Novel correction technique of chronic puerperal inversion of the uterus. J Obstet Gynaecol. 2007;27(2):197-8.
11. Shivanagappa M, Bhandiwad A, Mahesh M. A case of acute on chronic uterine inversion with fibroid polyp. J Clin Diagn Res. 2013;7(11):2587-88.

Cite this article as: Murde SG, Raut RR, Kumari B, Hojai DC. A rare case of acute non-puerperal uterine inversion due to large leiomyoma in COVID pandemic: challenges in clinical diagnosis and management. Int J Reprod Contracept Obstet Gynecol 2020;9:4765-8. 